RESEARCH PAPER RP703

Part of Journal of Research of the National Bureau of Standards, volume 13 August 1934

\title{
REFRACTIVE INDEX AND DISPERSION OF NORMAL AND HEAVY WATER
}

\author{
By L. W. Tilton and J. K. Taylor
}

\section{ABSTRACT}

Certain provisional values of the refractive index of normal water are given to accompany similar values determined at $25 \mathrm{C}$ by the minimum-deviation method for a sample of heavy water (sp gr $=1.001376$ at $25 \mathrm{C}$ ) using several wave lengths of the visible spectrum. According to the linear or additive relation for simple mixtures, which was found adequate in Luten's investigation, the differences in index between $\mathrm{H}_{2} \mathrm{O}$ and $\mathrm{H}_{2}^{2} \mathrm{O}$ are calculated and compared with previously published values.

According to a recent report by Luten ${ }^{1}$ the refractive index for mixtures of normal and heavy water may be correctly computed from the mol fractions according to the linear or additive relation for simple mixtures, at least to three significant figures in $\left(n_{1}-n\right)$ where $n_{1}$ and $n$ represent the indices of normal water and of a mixture, respectively. Proceeding in this manner Luten finds good agreement between his sodium $D$-line index for pure $\mathrm{H}_{2}^{2} \mathrm{O}$ and a result which he extrapolates from data for $\lambda=5,876 \mathrm{~A}$ published by Washburn, Smith, and Frandsen $^{2}$ of this Bureau, for a sample of water having a specific gravity of 1.001376 at $25 \mathrm{C}$. Consequently it is now of interest to publish certain additional index data which at that time (February 1933) were observed for the same sample but not hitherto carefully reduced because sufficiently precise comparison data on normal water were not readily available.

These measurements were made at $25.00 \mathrm{C}$ by the classical method of minimum deviation, using a water-jacketed hollow prism of $72^{\circ}$ refracting angle and $10-\mathrm{ml}$ capacity which was mounted in a stirred air bath on the spectrometer table. Temperatures were constant within $\pm 0.01^{\circ} \mathrm{C}$ during these measurements and were read to thousandths by use of a platinum resistance thermometer with its sensitive element immersed in the sample. Comparatively few observations were made but otherwise all precautions appropriate for precise index determinations ${ }^{3}$ were taken, just as is done in the absolute measurements on normal distilled water that are in progress in this refractometric laboratory, and all results refer to dry air of $760 \mathrm{~mm}$ pressure at the same temperature as that of the sample. Certain of these (provisional) values for the refractive index of normal water are given here (columns 2 and 3 of table 1) because the diversity among such published values precludes their satisfactory use for comparison with measured indices of heavy water.

1 Daniel B. Luten, Jr., Phys. Rev., 45, 161-165(1934).

2 Edward W. Washburn, Edgar R. Smith, and Mikkel Frandsen, J. Chem. Phys. 1, 288(1933); BS J.Research 11, 453-462(1933); RP601.

3 Many requisites for precision and accuracy in minimum-deviation measurements have previously been discussed. See L.W. Tilton, BS J.Research 2, 909-930(1929) RP64; 6, 59-76(1931) RP262; 11, 25-57(1933) RP575. 
TABLE 1.-Refractive index of water

( $n_{1}$ for $\mathrm{H}_{2} \mathrm{O}, n_{2}$ for $\mathrm{H}_{2} \mathrm{O}$, and $n$ for mixture)

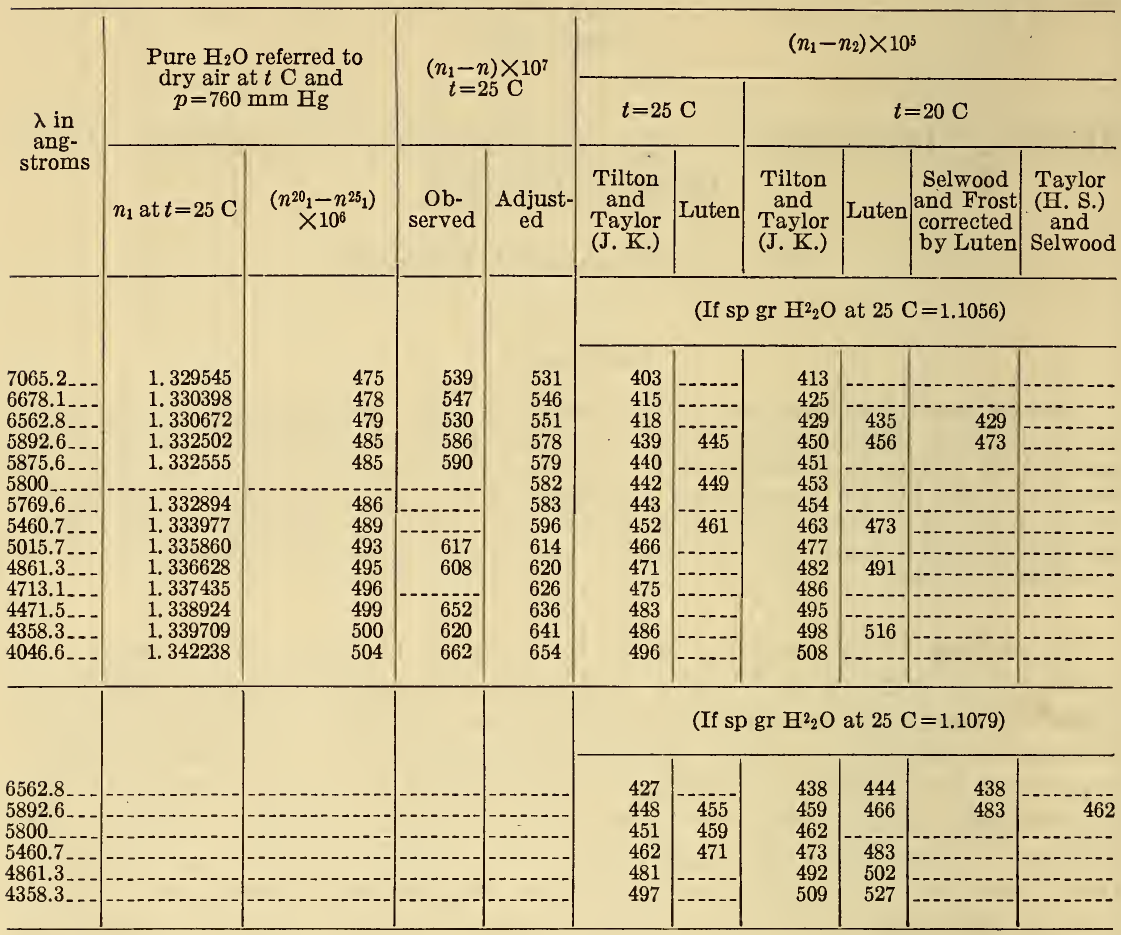

Referring to table 1 , the observed values of $\left(n_{1}-n\right) \times 10^{7}$ for the Washburn, Smith, and Frandsen mixture were used in determining, by the method of least squares, constants in the equation

$$
\left(n_{1}-n\right) \times 10^{7}=818.2-407.0 \lambda
$$

which (with $\lambda$ in microns) yields the corresponding adjusted values as tabulated for various wave lengths. Values of $\left(n_{1}-n_{2}\right)_{25} \times 10^{5}, n_{2}$ being the index for $\mathrm{H}_{2}^{2} \mathrm{O}$, were then computed from $\left(n_{1}-n\right) \times 10^{7}$. by the additive relation for mixtures after using Luten's nonlinear relation between specific gravity and composition to determine a value $N_{2}=0.01318$ for the mol fraction of $\mathrm{H}^{2}{ }_{2} \mathrm{O}$ in this particular sample of heavy water. Luten's temperature coefficients of index of $\mathrm{H}_{2}^{2} \mathrm{O}$ were used in deriving $\left(n_{1}-n_{2}\right)_{20} \times 10^{5}$. Table 1 also includes values of $\left(n_{1}-n_{2}\right) \times 10^{5}$ as reported by Luten and by other observers. ${ }^{4}$

Since Taylor and Selwood ${ }^{5}$ have announced a value of 1.1079 , instead of 1.1056 as previously used, for the specific gravity of $\mathrm{H}_{2}^{2} \mathrm{O}$ at $25 \mathrm{C}$ and also a refractive index determined for such water, all of these previously considered results have been revised and are recompared in the lower portion of table 1 . The new value for the mol fraction of the Washburn, Smith, and Frandsen sample of heavy water becomes 0.01290 .

4 P. W. Selwood and A. A. Frost, J. Am. Chem. Soc., 55, 4335(1933).

$\checkmark$ Hugh S. Taylor and P. W. Selwood, J. Am. Chem. Soc., 56, 998(1934). 
In general, the various values of $\left(n_{1}-n_{2}\right)$ show good agreement. It should be noticed that the extrapolation from the sample of specific gravity 1.001376 would propagate an error of 1 in the sixth decimal place of $n$ or $n_{1}$ to 8 in the fifth decimal of $n_{2}$. As compared with Luten's results, the slightly higher index and higher dispersion for the sample measured in this laboratory may, therefore, be the result of very slight systematic errors in measurement but it should be remembered, also, that Washburn, Smith, and Frandsen gave some results which indicate that some $\mathrm{O}^{18}$ should be present in this sample. According to the provisional data given by Lewis and Luten, ${ }^{6}$ an excess atom fraction of 0.001 for $\mathrm{O}^{18}$ would account for the difference in these values of $\left(n_{1}-n_{2}\right)$ as tabulated for wave length $5800 \mathrm{~A}$.

TABLE 2.-Dispersion of water for specified intervals of wave length

$\triangle n_{1} \times 10^{5}$ for normal water

\begin{tabular}{|c|c|c|c|c|c|c|c|c|}
\hline Observer & $\begin{array}{l}\text { Temper- } \\
\text { ature }\end{array}$ & $\begin{array}{l}4047 \text { to } \\
4358 \mathrm{~A}\end{array}$ & $\begin{array}{l}4358 \text { to } \\
4861 \mathrm{~A}\end{array}$ & $\begin{array}{l}4861 \text { to } \\
5461 \mathrm{~A}\end{array}$ & $\begin{array}{l}5461 \text { to } \\
5893 \mathrm{~A}\end{array}$ & $\begin{array}{l}5893 \text { to } \\
6563 \mathrm{~A}\end{array}$ & $\begin{array}{l}6563 \text { to } \\
7065 \mathrm{~A}\end{array}$ & $\begin{array}{l}4358 \text { to } \\
6563 \mathrm{~A}\end{array}$ \\
\hline Tilton and Taylor (J. K.) & $\begin{array}{r}{ }^{\circ} C_{25} \\
\quad 20\end{array}$ & $\begin{array}{l}252.8 \\
253.2\end{array}$ & $\begin{array}{l}308.1 \\
308.7\end{array}$ & $\begin{array}{l}265.1 \\
265.6\end{array}$ & $\begin{array}{l}147.5 \\
147.9\end{array}$ & $\begin{array}{l}183.1 \\
183.6\end{array}$ & $\begin{array}{l}112.7 \\
113.2\end{array}$ & $\begin{array}{l}903.8 \\
905.8\end{array}$ \\
\hline
\end{tabular}

$\triangle n_{2} \times 10^{5}$ for pure $\mathrm{H}_{2}{ }_{2} \mathrm{O}$

\begin{tabular}{|c|c|c|c|c|c|c|c|c|}
\hline $\begin{array}{l}\text { Tilton and Taylor (J. K.) } \\
\text { Luten } \\
\text { Selwood and Frost. }\end{array}$ & $\begin{array}{l}25 \\
20 \\
20\end{array}$ & 243 & $\begin{array}{l}292 \\
288\end{array}$ & $\begin{array}{l}247 \\
245\end{array}$ & $\begin{array}{l}134 \\
132\end{array}$ & $\begin{array}{l}162 \\
161 \\
160\end{array}$ & 97 & $\begin{array}{l}835 \\
826\end{array}$ \\
\hline
\end{tabular}

The apparent lower dispersion that might be inferred for $n_{2}$ from the Selwood and Frost values of $\left(n_{1}-n_{2}\right)$ is a result of the unusually high dispersion of the values which they tabulate for "ordinary water", namely, $\left(n_{D}-n_{c}\right) \times 10^{5}=199$ at $20 \mathrm{C}$. Their tabulated indices for all three solutions of heavy water yield reasonable values of dispersion and, as shown in table 2 , their computed results for $\mathrm{H}_{2}^{2} \mathrm{O}$ yield a difference, $n_{D}-n_{c}$, that is in good agreement with Luten's value and with the data of this paper.

Washington, May 28, 1934.

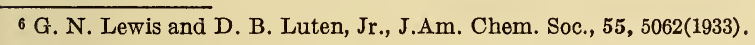

